\title{
Characterization and expression of uterine and placental alkaline phosphatases in the mouse
}

\author{
J. W. Pollard*, M. Jahan $\dagger$ and P. J. Butterworth $\dagger$ \\ *Department of Developmental Biology and Cancer, Albert Einstein College of Medicine, 1300 \\ Morris Park Ave., Bronx, NY 10461, USA; and †Department of Biochemistry, King's College, \\ Campden Hill Road, London W8 7 AH, UK
}

\begin{abstract}
Summary. Alkaline phosphatase (ALP) is rapidly induced in the uterine subepithelial stroma after a natural or artificial decidual stimulus. During gestation ALP-specific activity peaked at Day 7 to 8 (Day 1 is day of detection of the copulation plug) followed by a rapid decline to control levels by Day 9 . This elevation in enzyme activity was preceded by an 8 -fold induction of a 2.6 kilobase $(\mathrm{kb})$ mRNA. This mRNA was not preferentially localized to implantation sites. ALP activity was detected in the placenta at Day 9 and reached maximum specific activity at Day 19. The placental ALP was also encoded by a $2.6 \mathrm{~kb}$ mRNA. Uterine and placental ALPs were inhibited to the same extent by levamisole, L-tryptophan and homoarginine. The calculated $K_{\mathrm{i}}$ values for these inhibitors were not statistically different between the uterine and placental forms. $K_{\mathrm{m}}$ values towards the substrate $p$-nitrophenylphosphate, however, were statistically different between the uterine and placental forms. Both uterine and placental ALPs were stimulated 3-4-fold by addition of $2 \mathrm{mM}-\mathrm{Mg}^{2}{ }^{+}$. Electrophoretic mobilities on SDS polyacrylamide gel, where the enzyme migrated as a single band, were the same. The uterine form, however, could be distinguished from the placental isoenzyme by separation on non-denaturing polyacrylamide gels; the uterine form had a single zone of activity which migrated with an intermediate mobility between the two zones of activity detected for the placental enzyme. These differences in mobility could be ascribed to the sialic acid content of the enzyme because treatment with neuraminidase resulted in the uterine and placental forms migrating with comparable but slower mobilities in non-denaturing gels. The criteria of mRNA size, inhibitor sensitivity, SDS gel mobility and stimulation by $\mathrm{Mg}^{2}$ demonstrate that, in the mouse, the uterine and placental ALP belong to the bone-liver-kidney class of ALP.
\end{abstract}

Keywords: alkaline phosphatase; mouse; uterus; placenta; pregnancy

\section{Introduction}

Mammalian alkaline phosphatases (ALPs [orthophosphoric-monoester phosphohydrolase (alkaline optimum), EC 3.1.3.1]) are membrane-bound metalloenzymes of unknown function. Tissues such as small intestine, kidney proximal tubule and placenta, where a considerable degree of nutrient absorption or transport occurs, are particularly rich in the enzyme, but ALP is also found in osteoblasts, liver cells lining bile canaliculi, early embryo cells, primordial germ cells and teratocarcinoma stem cells (McComb et al., 1979; Crofton, 1982; Butterworth, 1983).

From extensive study of human ALPs it appears that the various tissue phosphatases are the products of at least three distinct genes that code respectively for intestinal, term placenta and the bone-liver-kidney (BLK) enzymes (Harris, 1982). The intestinal and placental forms exhibit certain similarities in kinetic properties such as inhibitor sensitivity, but both differ considerably in 
these regards from the BLK phosphatases (McComb et al., 1979; Cofton, 1982). 1solation and characterization of cDNAs that code for the three human types have shown that the similarities and differences in kinetic properties are a reflection of structural relationships; placental and intestinal ALPs are homologous whereas the BLK form is structurally distinct (Kam et al., 1985; Knoll et al., 1988; Weiss et al., 1988; Henthorn et al., 1988).

In contrast to man, ALPs in a number of other mammals including the rat and mouse are apparently elaborated from only two genes. One of these codes for intestinal ALP whereas the other gene is responsible for the production of the enzymes in other tissues (Wilcox et al., 1979; Wilcox \& Taylor, 1981). Cloned mouse cDNA for placental ALP has been used to demonstrate that the gene encoding this enzyme is identical to the gene expressed in mouse liver and kidney and in teratocarcinoma stem cells (Terao \& Mintz, 1987; Misumi et al., 1988; Thiede et al., 1988). In addition, it was shown that the predicted amino acid sequence of mouse placental phosphatase has $90 \%$ homology to human liver ALP, but only $55 \%$ homology to human placental enzyme (Terao \& Mintz, 1987).

In murids, one of the earliest events following decidualization is a dramatic induction of ALP activity. This induction is localized to the decidual cells and begins at the anti-mesometrial side from which it rapidly spreads around the uterus (Finn \& Hinchcliffe, 1964). It is therefore a good marker for decidual transformation. In mice and rats, the maximal uterine activity occurs 2-3 days following blastocyst implantation after which it declines sharply (Manning et al., 1969). Placental ALP activity increases, however, as this organ becomes established to reach its maximum towards term. In humans the particular characteristics of placental enzyme that distinguish it from intestinal and BLK forms make it a useful marker for the third trimester of pregnancy (Sussman et al., 1968). In mice it is not clear whether the uterine form can be distinguished from the placental isoenzyme or whether it is the product of the same or a different gene. In this study with mice we have applied various biochemical and molecular biological techniques to study the induction of uterine ALP and to compare and contrast placental and uterine forms of the enzyme. A brief summary of some of these results has already been reported (Jahan et al., 1988).

\section{Materials and Methods}

Assay of ALP activity. Assays were conducted in reaction volumes of $2 \mathrm{ml}$ at $\mathrm{pH} 9 \cdot 5$ and $30^{\circ} \mathrm{C}$ in $0 \cdot 1 \mathrm{M}$-diethanolamine buffer containing $1 \mathrm{~mm}-\mathrm{MgSO}_{4}$ plus $2.5 \mathrm{~mm}$-p-nitrophenylphosphate as a substrate. The reaction was started by the addition of a suitable volume of enzyme (usually 10-100 $\mu$ ) and continued for $10 \mathrm{~min}$ before termination by the addition of $1 \mathrm{ml} 0 \cdot 5 \mathrm{M} \cdot \mathrm{NaOH}$. The concentration of liberated $p$-nitrophenol was calculated from the absorption at $400 \mathrm{~nm}$ using the extinction coefficient of $18.6 \mathrm{~m}^{-1} \mathrm{~cm}^{-1}$. A unit of activity corresponds to the formation of $1 \mu \mathrm{mol}$ product/min.

For kinetic and inhibitor studies, the reaction mixture was modified appropriately to give the required range of substrate and/or inhibitor concentrations. The inhibitors were dissolved in the diethanolamine buffer and readjusted to $\mathrm{pH} 9.5$ if necessary. Inhibitor data were plotted in the form of (S)/V against (1) after Cornish-Bowden (1974). Kinetic constants were obtained from weighted regression analysis of data (Wilkinson, 1961; Shirazi et al., 1981).

Extraction of ALP. Tissue obtained from mouse uterus, intestine, kidney and placenta was homogenized separately at $4^{\circ} \mathrm{C}$ in $5 \mathrm{ml} 0.01 \mathrm{M}$-Tris $-\mathrm{HCl}, \mathrm{pH} \mathrm{7.4}$, containing $1 \mathrm{mM}-\mathrm{MgSO}_{4}$ and $10 \mu \mathrm{M}-\mathrm{ZnSO}_{4}$ to which $3 \mathrm{ml} n$-butanol were added. Each homogenate was stirred for $20 \mathrm{~min}$ at $20^{\circ} \mathrm{C}$ and then centrifuged at $15000 \mathrm{~g}_{\mathrm{av}}$ for $30-40 \mathrm{~min}$. The separated aqueous layer containing extracted ALP was removed using a Pasteur pipette.

Treatment with neuraminidase. Extracted enzyme was concentrated 10-fold in an Amicon Miniconcentrator and then $0.1 \mathrm{ml}$ of the concentrate was added to $0.4 \mathrm{ml} 0.05 \mathrm{M}$-acetate buffer, $\mathrm{pH} 5$. Neuraminidase $(0.1$ Unit) was added and the mixture incubated for up to $30 \mathrm{~min}$ at $37^{\circ} \mathrm{C}$. Controls, consisting of identical mixtures except that neuraminidase was replaced by buffer, were incubated in parallel. All samples were then subjected to electrophoresis.

Electrophoresis. Electrophoresis in $7.5 \%$ polyacrylamide slab gels containing sodium dodecyl sulphate was performed by the method of Laemmli (1970). Tissue extracts were concentrated approximately 10 -fold and then treated with $2 \%$ sodium dodecyl sulphate at $30^{\circ} \mathrm{C}$ for $3 \mathrm{~min}$ before being loaded onto the gel. Electrophoresis was also carried out under non-denaturing conditions, i.e. sodium dodecyl sulphate was omitted from the gel, and the enzyme samples were not pretreated with detergent before electrophoresis. 
At the conclusion of the run, gels were soaked for $24 \mathrm{~h}$ in $0.1 \mathrm{M}$-Tris- $\mathrm{HCl}$ buffer, $\mathrm{pH} 9 \cdot 4$, to remove the inhibitory glycine and then zones of ALP were detected by a histochemical method (Ramasamy \& Butterworth, 1974).

Protein assay. This was measured by the Coomassie Blue staining method of Bradford (1976) using bovine serum albumin as standard.

Preparation and analysis of RNA. RNA was extracted from uteri and placenta by a modification of the guanidium isothiocyanate method of Chirgwin et al. (1974) as previously described (Cheng \& Pollard, 1986). Total RNA samples $(20 \mu \mathrm{g})$ were separated by formaldehyde gel electrophoresis, blotted onto Hybond nitrocellulose membranes (Amersham) and probed using a $\left[{ }^{32} \mathrm{P}\right] \mathrm{dCTP}$-labelled rat ALP cDNA clone (pRAP54; Thiede et al., 1988) as described (Pollard et al., 1987). Blots were washed to a final stringency of $1 \times \operatorname{SSC}(0.15 \mathrm{M} \cdot \mathrm{NaCl}, 0.015 \mathrm{M}$-trisodium citrate, $\mathrm{pH} \mathrm{7.4)} \mathrm{at} 52^{\circ} \mathrm{C}$. Blots were re-probed with pxlr101A, a Xenopus ribosomal probe, to detect 28S and 18S RNA in order to use this as an internal standard for loading and transfer (Arceci et al., 1989). After autoradiography using Kodak X-OMAT film, autoradiograms were scanned using an LKB scanning laser densitometer. Values for the ALP mRNA were expressed relative to the density of $18 \mathrm{~S}$ rRNA band.

Animals. Mice of a closed but not inbred colony of the Schneider strain (Cheng et al., 1985) were paired overnight and inspected for a vaginal plug the following morning. The presence of a plug was used to index the first day of pregnancy. Animals were killed by cervical dislocation at the appropriate times and tissues processed as described above.

\section{Results}

\section{ALP expression during gestation}

The uterine ALP-specific activity in ovariectomized control animals was approximately $50 \%$ of that measured in randomly cycling animals $(0.09 \mathrm{U} / \mathrm{mg} \pm 0.02, \mathrm{~N}=6$, and $0.17 \mathrm{U} / \mathrm{mg} \pm 0.03$, $\mathrm{N}=6$, respectively; $P<0.05$, Student's $t$ test). During gestation statistically elevated concentrations, compared to those of randomly cycling animals, of uterine ALP were detected at Day 6 ( $P<0.005$, Student's $t$ test). The specific activity peaked at Day 7 of pregnancy when it was approximately $3 \cdot 6$-fold greater than the uterine values of randomly cycling animals. The specific activity fell by Day 9 to a level that was about double that of the ovariectomized controls but equivalent to that of randomly cycling animals. The concentration continued to decline throughout the remainder of gestation. ALP activity was detected in the placenta at Day 9 and reached a maximum at Day 19 immediately before parturition. At Day 19 the enzymic specific activity was approximately 5-fold greater than the control value in uteri of ovariectomized females.

Elevated amounts of a $2 \cdot 6$ kilobase $(\mathrm{kb})$ ALP mRNA were detected at Day 5 of pregnancy with a peak at Day 6 (Fig. 2). This represented an 8-fold induction of the mRNA. On some Northern blots a minor band could also be detected at approximately $3.0 \mathrm{~kb}$. Because the RNA was total cellular RNA this could be a nuclear precursor or the product of an alternatively spliced mRNA species. There was no preferential expression of the ALP mRNA in uterine implantation areas at Day 7 or Day 8 (Fig. 2). Expression of an ALP mRNA of the same size was also detected in the placenta at Day 9 and the level of this increased steadily in the placenta until Day 17 (Fig. 2).

\section{Characterization of uterine and placental ALP}

The sensitivity of ALP to a number of inhibitors was tested throughout the whole of gestation. With all the inhibitors tested, namely levamisole, L-tryptophan and homoarginine, the degree of inhibition that each produced was constant throughout the observation period (Fig. 1, and data not shown). No differences in sensitivity between the uterine and placental enzymes were detected (Table 1).

The nearly identical sensitivity to homoarginine is evidence that uterine and placental ALPs are structurally related. This possibility was examined further by a comparison of some kinetic properties of enzymes extracted from uterus at Day 7 and from placenta at Day 19. ALPs extracted from intestine and kidney were also included in the examination. Uterine, placental and kidney enzymes were all inhibited potently by L-homoarginine in a classical non-competitive manner (Fig. 3). 


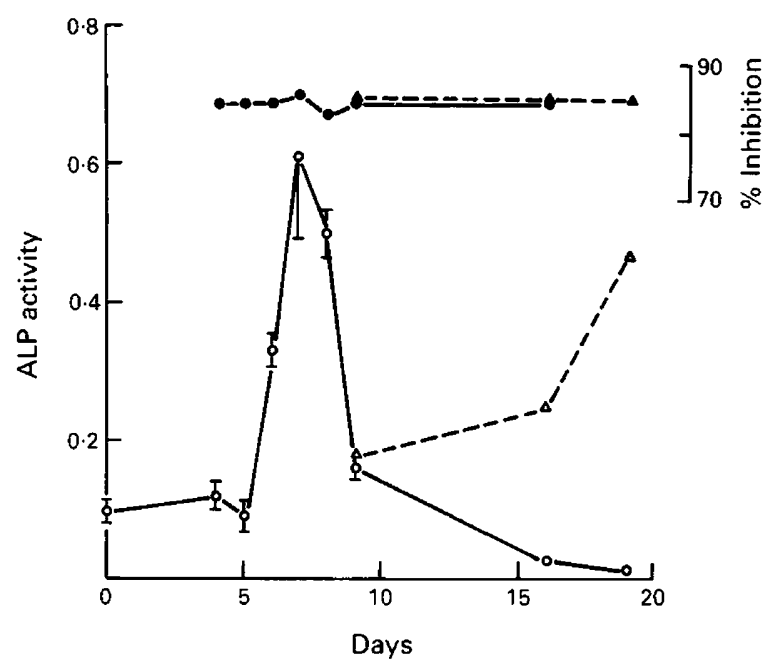

Fig. 1. Uterine $(O, O)$ and placental $(\triangle, \boldsymbol{\Delta})$ alkaline phosphatases of the mouse during pregnancy. $\boldsymbol{O}, \boldsymbol{\Delta}=\%$ inhibition by $4 \mathrm{~mm}$-homoarginine. Values are mean \pm s.e.m. of $3-6$ determinations.

(a) ALP

(b) rRNA

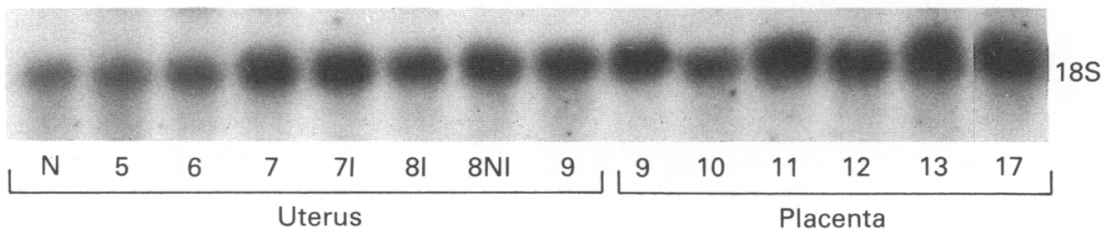

Fig. 2. Detection of ALP mRNA in the mouse uterus and placenta. Autoradiograph of a Northern blot of total uterine or placental RNA derived from individual animals at the days of gestation shown. RNA samples $(20 \mu \mathrm{g} / \mathrm{lane})$ were separated by formaldehyde agarose gel electrophoresis, transferred onto Hybond and probed with radiolabelled rat ALP CDNA (a) as described in the 'Materials and Methods'. After suitable exposure, blots were reprobed with a cDNA to Xenopus rRNA (b) to quantify the amount of RNA in each lane to correct for variation in loading and transfer of RNA. The experiment shown was repeated 3 times with similar results. $\mathbf{N}=$ randomly cycling non-pregnant animal; $\mathbf{I}=$ implantation site; $\mathrm{NI}=$ nonimplantation site.

Intestinal ALP, in contrast, was unaffected by homoarginine at the concentrations tested. The calculated $K_{\mathrm{i}}$ values obtained for uterus and placenta were nearly identical but differed a little from the value for kidney. $K_{\mathrm{m}}$ values towards $p$-nitrophenylphosphate differed, with the kidney enzyme having a value intermediate between uterine and placental forms (Table 2). After overnight dialysis of the uterine extract against $0.01 \mathrm{M}-\mathrm{Tris}-\mathrm{HCl}$ buffer $\mathrm{pH} 7.6$ to remove $\mathrm{Mg}^{2+}$ from the extract, uterine ALP was stimulated 3-4-fold by the addition of up to $2 \mathrm{mM}-\mathrm{Mg}^{2+}$. 
Table 1. Sensitivity of uterine and placental alkaline phosphatases to various inhibitors

\begin{tabular}{lccc}
\hline & \multicolumn{3}{c}{$\%$ Inhibition } \\
\cline { 2 - 4 } & $\begin{array}{c}\text { Levamisole } \\
(10 \mathrm{mM})\end{array}$ & $\begin{array}{c}\text { Tryptophan } \\
(2 \mathrm{mM})\end{array}$ & $\begin{array}{c}\text { Homoarginine } \\
(4 \mathrm{mM})\end{array}$ \\
\hline Uterine & $67.8 \pm 0.8(5)$ & $9 \cdot 7 \pm 1 \cdot 1 \quad(6)$ & $86.2 \pm 0.6 \quad(4)$ \\
Placental & $69.4 \pm 0.5 \dagger(3)$ & $10 \cdot 3 \pm 1.0 \dagger(3)$ & $85.8 \pm 0.5+(4)$ \\
\hline
\end{tabular}

The values are mean \pm s.e.m. for the no. of observations in parentheses, calculated from data obtained for Days 5-9 and 9-19 for uterus and placenta respectively.

$\uparrow$ Not statistically different from the uterine value.

Table 2. Kinetic properties of mouse alkaline phosphatases

\begin{tabular}{lcl}
\hline Tissue source of ALP & $K_{\mathrm{m}}(\mathrm{mM})$ & \multicolumn{1}{c}{$K_{\mathrm{j}}(\mathrm{mM})$} \\
\hline Kidney & $0.076 \pm 0.01$ & $0.99 \pm 0.1$ \\
Uterus (Day 7) & $0.036 \pm 0.01$ & $0.52 \pm 0.04$ \\
Placenta (Day 19) & $0.14 \pm 0.03$ & $0.61 \pm 0.05$ \\
\hline
\end{tabular}

The kinetic constants were determined at $\mathrm{pH} 9.5$ using $p$ nitrophenolphosphate as substrate. The $K_{\mathrm{i}}$ values refer to homoarginine. The values are the mean \pm s.e.m.
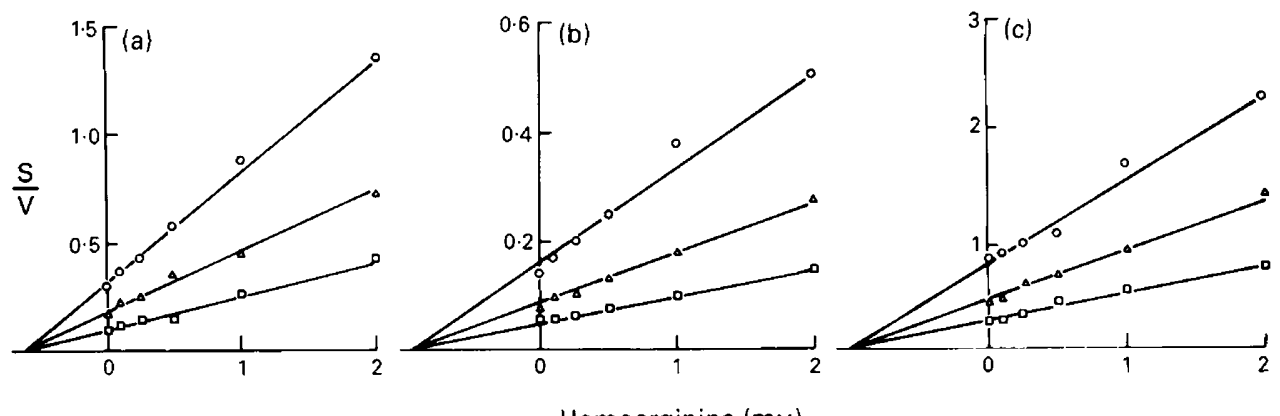

Fig. 3. Inhibition of mouse alkaline phosphatase by homoarginine. The data are plotted in the form of (S)/V against (I) after Cornish-Bowden (1974). (a) Uterine (Day 7) ALP; (b) placental (Day 19) ALP; (c) kidney ALP. In each case the inhibition was studied at substrate concentrations of $0.125 \mathrm{~mm}(\square), 0.25 \mathrm{~mm}(\triangle)$ and $0.5 \mathrm{~mm}(\bigcirc)$. ALP activity represents units/ml enzyme.

Placental and uterine enzymes migrated as single bands with the same mobility in sodium dodecyl sulphate polyacrylamide gels. Both of these forms could be distinguished from kidney and intestinal enzymes (Fig. 4a). On electrophoresis in non-detergent polyacrylamide gels, however, although the uterine (Fig. 4b) and kidney (data not shown) enzymes migrated as a single zone of activity with the same mobility, the placental enzyme separated into 2 components with most of the activity being detected as a faster moving band. After digestion with neuraminidase for $15 \mathrm{~min}$, the placental and uterine enzymes appeared as single zones with comparable but slower mobilities (Fig. 4b). In 
detergent-containing gels (Fig. 4a), the placental enzyme, which had not been exposed to neuraminidase, migrated as a single band, supporting the conclusion reached from the neuraminidase experiments that charge difference is the cause of heterogeneity seen in non-detergent gels.

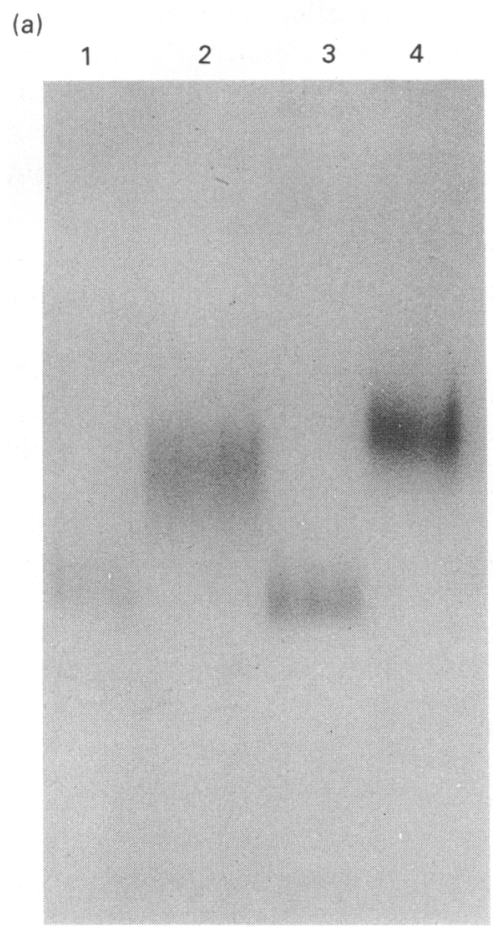

(b)

Fig. 4. Polyacrylamide gel electrophoresis of mouse alkaline phosphatases. (a) SDS $7.5 \%$ polyacrylamide gel of Day-7 uterine (lane 1), kidney (lane 2), Day-19 placental (lane 3) and intestinal (lane 4) ALPs. (b) Non-denaturing polyacrylamide gel electrophoresis of Day-7 uterine (lanes 1 and 4), Day-18 placental (lanes 2 and 5) and Day-19 placental (lanes 3 and 6) ALP. Before electrophoresis samples were incubated for $15 \mathrm{~min}$ with (lanes 1-3) or without (lanes 4-6) neuraminidase. After electrophoresis in (a) and (b), gels were soaked for $24 \mathrm{~h}$ in $0 \cdot 1 \mathrm{M}$ Tris- $\mathrm{HCl}, \mathrm{pH} 9 \cdot 4$, and then the zones of ALP were detected as described in the "Materials and Methods'. All gels were run at least 3 times with similar results.

\section{Discussion}

Decidualization causes an elevation of ALP-specific activity which attains a peak 2-3 days after implantation. This pattern is similar to that reported for rats (Manning et al., 1969) and mice (Finn \& Hinchcliffe, 1964; Hall, 1969; Murdoch et al., 1978). The induction of enzyme activity was preceded by an elevation in a $2.6 \mathrm{~kb}$ ALP mRNA which reached a peak 8 -fold over the control level at Day 6. Manning et al. (1969) were unable to inhibit the elevation of ALP-specific activity induced by traumatizing progesterone-primed rat uteri with inhibitors of transcription (actinomycin-D), replication (5-flurodeoxyuridine) or translation (cycloheximide, chloramphenicol). This led these workers to postulate that the ALP induction was due to post-translational activation of a preexisting pro-enzyme. It is unclear why these inhibitors did not prevent the ALP rise because the present studies show that there was a clear elevation of ALP mRNA correlating with the induction of ALP activity. 5-Flurodeoxyuridine and inhibitors of protein synthesis that inhibit DNA synthesis as a consequence of their actions also failed to reduce the decidual response in the studies of 
Manning et al. (1969), despite the fact that decidualization involves substantial cell proliferation (Hall, 1969; Das \& Martin, 1978). No measurements of the degree of inhibition of protein or RNA synthesis were performed by Manning et al. (1969). Since it is difficult to reduce RNA synthesis profoundly when actinomycin-D is adminstered systemically (Pollard et al., 1976) the most likely resolution of the paradoxical data is that the inhibitors failed to reach effective concentrations for sufficiently long duration to inhibit ALP mRNA accumulation and translation. Alternatively, it is possible that the traumatization of the uterus used by Manning et al. (1969) to induce decidualization, which does not require oestrogen (Finn 1971), might result in a different mechanism for ALP induction than that observed during pregnancy with its absolute requirement for nidatory oestrogen (Finn, 1971).

The decidual specific expression of ALP (Finn \& Hinchcliffe, 1964; Manning et al., 1969; Hall, 1969), however, does appear to be governed by regulatory mechanisms over and above the induction of ALP mRNA. ALP mRNA was not preferentially localized to implantation sites even though enrichment of the mRNA for another decidual marker, the colony stimulating factor-1 receptor, was observed in these areas (Arceci et al., 1989). This suggests that expression of ALP is regulated either by the specific translation of the ALP mRNA in the decidua, or the deciduaspecific activation of a newly synthesized pro-enzyme as suggested by Manning et al. (1969).

From genetic and molecular genetic studies of mice, placental ALP appears to be encoded by the same gene that encodes the BLK form of the enzyme (Wilcox \& Taylor, 1981; Terao \& Mintz, 1987; Thiode et al., 1988), the intestinal enzyme being derived from a separate gene. The major human placental form, however, can be distinguished from the human BLK form by its mRNA size (3.0 vs $2.6 \mathrm{~kb}$; Ovitt et al., 1986), its sensitivity to specific inhibitors (McComb et al., 1979; Crofton, 1982) and its nucleotide sequence (Ovitt et al., 1986). The human placental form therefore appears to be more evolutionarily recent than the rodent divergence (Harris, 1982) and produced by a duplication and divergence of the intestinal specific gene (Ovitt et al., 1986). Mouse uterine ALP mRNA is $2.6 \mathrm{~kb}$. This is the size of mouse placental ALP mRNA reported in this study and in the study by Terao \& Mintz (1987). Therefore, based on mRNA size, inhibitor (particularly homoarginine) sensitivity, and SDS polyacrylamide gel electrophoretic mobility, uterine and placental ALP are in the same class of enzyme. Thus, by these criteria, as well as the pronounced stimulation of uterine ALP activity by $\mathrm{Mg}^{2+}$, a characteristic of the BLK form of the enzyme, uterine ALP is derived from the same gene as the BLK enzyme. Despite their assumed common primary sequence, however, it is possible to distinguish the uterine enzyme from the placental form by non-denaturing gel electrophoresis. Under these conditions the placental enzyme exhibits a fast and slow electrophoretic form which both have mobilities different from that of the single uterine band. These forms are distinguishable because of their sialic acid content, since neuraminidase treatment before electrophoresis resulted in the uterine and placental forms exhibiting similar, but slower, mobilities on non-denaturing gels. These results further support the conclusion that these isoenzymes are all derived from the same primary translation product. The difference in sialic acid content may, however, explain the difference in $K_{\mathrm{m}}$ between uterine and placental ALP. This ability to distinguish between the placental and uterine ALP isoenzymes on non-denaturing gels may prove to be useful as a cell marker in fractionation procedures designed to enrich for either decidual or placental cells.

We thank Dr M. Thiede for providing the rat ALP cDNA and Frances Shanahan for excellent technical help. This work was supported by a grant from the King's Biochemistry Faculty Development Fund (P.J.B.) and to J.W.P. by a National Institute of Health grant (HD25074-01) and the Albert Einstein Core Cancer grant, P30-CA 1330.

\section{References}

Arceci, R.J., Shanahan, F., Stanley, E.R. \& Pollard, J.W. (1989) Temporal expression and location of colony stimulating factor- 1 (CSF-1) and its receptor in the female reproductive tract are consistent with CSF-1 regulated placental development. Proc. natn. Acad. Sci. USA 86, 8818-8822.

Bradford, M.M. (1976) A rapid and sensitive method for the quantitation of microgram quantities of protein Downloaded from Bioscientifica.com at 04/26/2023 12:31:12AM 
utilizing the principle of protein-dye binding. Analyt. Biochem. 72, 248-254.

Butterworth, P.J. (1983) Alkaline phosphatasebiochemistry of mammalian alkaline phosphatases. Cell Biochem. Function 1, 66-70.

Cheng, S.V.Y. \& Pollard, J.W. (1986) c-ras ${ }^{\mathbf{H}}$ and ornithine decarboxylase are induced by oestradiol- $17 \beta$ in the mouse uterine luminal epithelium independently of the proliferative status of the cell. FEBS Letts. 196, 309-314.

Cheng, S.V.Y., MacDonald, B.S., Clark, B.F. \& Pollard, J.W. (1985) Cell growth and cell proliferation may be dissociated in the mouse uterine luminal epithelium treated with female sex steroids. Expl Cell Res. 160, $459-470$.

Chirgwin, J.M., Przybyla, A.E., MacDonald, R.J. \& Rutter, W.J. (1974) Isolation of biologically active ribonucleic acid from sources enriched in ribonuclease. Biochemistry, NY 18, 5294-5299.

Cornish-Bowden, A. (1974) A simple graphical method for determining the inhibition constants of mixed, uncompetitive and non-competitive inhibitors. Biochem. $J$. 137, 143-144.

Crofton, P.M. (1982) Biochemistry of alkaline phosphatase isoenzymes. CRC Crit. Reviews Clin. Lab. Sci. 16, 161-194.

Das, R.M. \& Martin, L. (1978) Uterine DNA synthesis and cell proliferation during early decidualization induced by oil in mice. J. Reprod. Fert. 53, 125-128.

Finn, C.A. (1971) The biology of decidual cells. $A d v$. Reprod. Physiol. 5, 1-26.

Finn, C.A. \& Hinchcliffe, J.R. (1964) Reaction of the mouse uterus during implantation and deciduoma formation as demonstrated by changes in the distribution of alkaline phosphates. J. Reprod. Fert. 8, 331-338.

Hall, K. (1969) Uterine mitosis, alkaline phosphatase and adenosine triphosphatase during development and regression of deciduomata in pseudopregnant mice. J. Endocr. 44, 91-100.

Harris, H. (1982) Multilocus enzyme systems and the evolution of gene expression: The alkaline phosphatases as a model example. Harvey Lect. 76, 95-123.

Henthorn, P.S., Raducha, M., Kadesch, T., Weiss, M.J. \& Harris, H. (1988) Sequence and characterization of the human intestinal alkaline phosphatase gene. $J$. biol. Chem. 263, 12011-12019.

Jahan, M., Pollard, J.W. \& Butterworth, P.J. (1988) Hormonal regulation of mouse uterine alkaline phosphatase. Biochem. Soc. Trans. 16, 848-849.

Kam, W., Clauser, E., Kim, Y.S., Kan, Y.W. \& Rutter, W.J. (1985) Cloning, sequencing and chromosomal localization of human term placental alkaline phosphatase cDNA. Proc. natn. Acad. Sci. USA 82, 8715-8719.

Knoll, B.J., Rothblum, K.N. \& Longley, M., (1988) Nucleotide sequence of the human placental alkaline phosphatase gene: evolution of the $5^{\prime}$ flanking origin by deletion/substitution. J. biol. Chem. 263, 12020-12027.

Laemmli, U.K. (1970) Cleavage of structural proteins during the assembly of the head of bacteriophage T4. Nature, Lond. 227, 680-685.
Manning, J.P. Steinetz, B.G. \& Giannina, T. (1969) Decidual alkaline phosphatase activity in the pregnant and pseudopregnant rat. Ann. N.Y. Acad. Sci. 166, $482-509$.

McComb, R.B., Bowers, G.N. \& Posens, S. (1979) Alkaline Phosphatase. Plenum Press, New York.

Misumi, Y., Tashiro, K., Hattori, M.,Sakaki, Y. \& Ikehara, Y. (1988) Primary structure of rat liver alkaline phosphatase deduced from its cDNA. Biochem. J. 249 , 661-668.

Murdoch, R.N. Kay, D.J. \& Cross, M. (1978) Activity and subcellular distribution of mouse uterine alkaline phosphatase during pregnancy and pseudopregnancy. J. Reprod. Fert. 54, 293-300.

Ovitt, C.E., Strauss, A.W., Alpers, D.H., Chou, J.Y. \& Boime, I. (1986) Expression of different-sized placental alkaline phosphatase mRNAs in placental and choriocarcinoma cells. Proc. natn. Acad. Sci. USA 33, 3781-3785.

Pollard, J.W., Finn, C.A. \& Martin, L. (1976) Actinomycin D and uterine epithelial protein synthesis. $J$. Endocr. 69, 16!-162.

Pollard, J.W., Bartocci, A., Arceci, R.J., Orlofsky, A., Ladner, M.B. \& Stanley, E.R. (1987) Apparent role of the macrophage growth factor, CSF-1, in placental development. Nature, Lond. 330, 484-486.

Ramasamy, I. \& Butterworth, P.J. (1974) Subunit structure and catalytic activity of pig kidney alkaline phosphatase. Biochim. Biophys. Acta 370, 477-486.

Shirazi, S.P., Beechey, R.B. \& Butterworth, P.J. (1981) Potent inhibition of a membrane-bound rat intestinal alkaline phosphatase by a new series of phosphate analogues. Biochem. J. 194, 797-802.

Sussman, H.H., Bowman, M. \& Lewis, J.L. (1968) Placental alkaline phosphatase in maternal serum during normal and abnormal pregnancy. Nature, Lond. 218, 359-360.

Terao, M. \& Mintz, B. (1987) Cloning and characterization of a cDNA coding for mouse placental alkaline phosphatase. Proc. natn. Acad. Sci. USA 84, $7051-7055$.

Thiede, M.A., Yoon, K., Golub, E.E., Noda, M. \& Rodan, G.A. (1988) Structure and expression of rat osteosarcoma (ROS 17/2.8) alkaline phosphatase: Product of a single copy gene. Proc. natn. Acad. Sci. USA 85, 319-323.

Weiss, M.J., Ray, K., Henthorn, P.S., Lamb, B., Kadesch, T. \& Harris, H. (1988) Structure of the human liver/bone/kidney alkaline phosphatase gene. J. biol. Chem. 263, 12002-12010.

Wilcox, F.H. \& Taylor, B.A. (1981) Genetics of the ALp2 locus for alkaline phosphatase of liver, kidney, bone and placenta in the mouse. Linkage with ALd-1 locus on chromosomes 4. J. Hered. 72, 387-390.

Wilcox, F.H., Hirschorn, L., Taylor, B.A., Womack, J.E. \& Roderick, T.H. (1979) Genetic variation in alkaline phosphatase of the house mouse (Mus musclus) with emphasis on a manganese-requiring isozyme. Biochem. Genet. 17, 1093-1107.

Wilkinson, G.N. (1961) Statistical estimations in enzyme kinetics. Biochem. J. 80, 324-333.

Received 2 January 1990 